\title{
ANÁLISE DO COMPORTAMENTO CARONISTA NO COMÉRCIO ELETRÔNICO
}

\author{
CERIBELI, Harrison Bachion ${ }^{1}$ \\ CONTE, Gabriel Manthay ${ }^{2}$
}

\begin{abstract}
RESUMO: Esta pesquisa teve como objetivo analisar se os fatores que explicam a adoção do comércio eletrônico são também capazes de explicar o comportamento caronista dos e-consumidores. Para atingir o objetivo proposto, foi realizado um levantamento de campo, com amostra composta por 307 indivíduos. Para a análise dos dados, utilizouse a Análise Fatorial Exploratória e a Análise de Regressão Múltipla. A partir dos resultados obtidos nas análises estatísticas, constatou-se que existem alguns fatores que motivam a adoção do comércio eletrônico e que influenciam diretamente a adoção do comportamento caronista, sendo eles (1) a percepção de que é possível encontrar preços mais baixos nas compras realizadas pela Internet, (2) a percepção de maior conveniência nas compras efetuadas online, (3) a percepção reduzida de risco associada ao e-commerce, e (4) a pré-disposição em buscar mais informações prévias em redes sociais, com terceiros que fazem dos grupos sociais com os quais se possui contato ou com base em experiências anteriores.
\end{abstract}

Palavras-chave: Comércio eletrônico. Comportamento caronista. E-consumidor.

SUMMARY: This research aimed to analyze if the factors that explain the adoption of electronic commerce are also able to explain the free-rider behavior of the e-consumers. To achieve the proposed objective, a field survey was conducted with a sample of 307 individuals. For data analysis, we used the Exploratory Factor Analysis and Multiple Regression Analysis. From the results obtained in the statistical analyzes, it was found that there are some factors that motivate the adoption of electronic commerce that directly influence the free-rider behavior, which are the perception of low prices and convenience, both related with e-commerce, low perception of risk associated with online shopping, and search of prior information in social networks, with others consumers or based in previous experiences.

Keywords: E-commerce. Free rider behavior. E-consumer.

\section{INTRODUÇÃO}

No ano de 2015, as vendas no varejo restrito brasileiro (que exclui veículos, materiais de construção e combustíveis) acumularam queda de quase 4\%. O comércio eletrônico, por outro lado, registrou, no mesmo ano, um aumento de $15,3 \%$ em seu faturamento, evidenciando o ímpeto de crescimento do setor, que recebeu 106,5 milhões de pedidos, provenientes de 39,1 milhões de econsumidores, como são chamados os consumidores do comércio eletrônico (EBIT, 2016).

Caracterizando o consumidor que comprou no comércio eletrônico brasileiro em 2015, tem-se que $39 \%$ possuem renda mensal de até $\mathrm{R} \$ 3$ mil, $42 \%$ recebem entre $\mathrm{R} \$ 3$ mil e $\mathrm{R} \$ 8$ mil e $19 \%$ auferem ganhos mensais superiores a R \$8 mil (EBIT, 2016). 8\% dos e-consumidores têm até 24 anos, 21\%, entre 25 e 34 anos, 39\%, entre 35 e 49 anos e 33\% possuem 50 anos ou mais (EBIT, 2016). São Paulo, Rio de Janeiro e Minas Gerais são os Estados que concentram a maior parte das compras virtuais no país, representando, juntos, $62 \%$ do total (EBTI, 2016).

\footnotetext{
${ }^{1}$ Vice-direto $r$ do Instituto de Ciências Sociais Aplicadas (ICSA-UFOP), Professor Adjunto da Universidade Federal de Ouro Preto (UFOP), Doutor em Administração pela Universidade de São Paulo (FEARP-USP).

${ }^{2}$ Graduado em Administração pela Universidade Federal de Ouro Preto (UFOP)
} 
Analisando o período de cinco anos entre 2011 e 2015, o volume de vendas no comércio eletrônico no Brasil obteve crescimento de, aproximadamente, $121 \%$, saltando de $\mathrm{R} \$ 18,7$ milhões em 2011 para R \$41,3 milhões em 2015 (EBIT, 2016). Em relação ao ano anterior, o faturamento do comércio eletrônico no país cresceu 20,3\% em 2012, $28 \%$ em 2013, 24,3\% em 2014 e, 15,3\% em 2015, ano marcado por forte recessão na economia nacional (EBIT, 2016). Todos esses dados evidenciam a consolidação da expansão do e-commerce, que tem apresentado evolução contínua e significativa.

No comércio eletrônico, existe uma tendência ao comportamento caronista ou free rider, que ocorre quando o e-consumidor visita um website que disponibiliza mais informações sobre um determinado produto e, após se informar, busca outro website que ofereça o mesmo produto com um preço menor (SPAHN, 2013; CARLTON; CHEVALIER, 2001; BAKOS, 2001; VAN BAAL; DACH, 2005).

Ao analisar as publicações sobre o comportamento do e-consumidor nas bases Scopus, Web of Science e Spell, constatou-se que existem diversas pesquisas que levantaram os fatores teóricos que podem ser apontados como antecedentes da adoção do comércio eletrônico; todavia, faltam estudos sobre os antecedentes do comportamento caronista, sendo esta uma lacuna teórica a ser preenchida.

Baseando-se em tal constatação, definiu-se como objetivo desta pesquisa analisar se os fatores que explicam a adoção do comércio eletrônico são também capazes de explicar o comportamento caronista do e-consumidor.

A importância deste estudo se apoia inicialmente no crescimento consistente do comércio eletrônico no Brasil, o que vem tornando este setor uma peça importante para a economia do país. A cada ano, desde sua introdução ao Brasil, esta modalidade de comércio vem evoluindo exponencialmente; sendo assim, o contexto definido para este trabalho se mostra de grande potencial econômico.

Em segundo lugar, destaca-se a importância do tema comportamento caronista, considerando que as organizações se preocupam com as perdas geradas devido a consumidores que apresentam este comportamento. É relevante entender o comportamento caronista para que as organizações possam buscar maneiras para reduzir suas perdas financeiras associadas a ele.

Por fim, destaca-se a escassez de trabalhos de cunho científico que tenham como foco o estudo do comportamento caronista, tanto do Brasil quanto no âmbito internacional. Analisando apenas pesquisas sobre o tema realizadas no Brasil, a escassez se mostra ainda mais crítica, o que demonstra a importância do estudo e justifica a escolha deste tema.

\section{REFERENCIAL TEÓRICO}

\subsection{Comércio eletrônico}

Kalakota e Whinston (1997) defendem que o conceito de comércio eletrônico deve ser analisado a partir de quatro perspectivas complementares: (1) comunicação; (2) processo de negócio; (3) serviços; e (4) conectividade.

Partindo de uma perspectiva focada na comunicação, o comércio eletrônico pode ser conceituado como um processo de entrega de informações, produtos e serviços ancorado em redes de computadores, linhas telefônicas ou quaisquer tecnologias de comunicação (KALAKOTA; WHINSTON, 1997; STRADER; SHAW, 1997). Sob a perspectiva de processo de negócio, o comércio eletrônico pode ser entendido como um processo baseado na aplicação de tecnologias que possibilitam a automação das transações de negócios e do fluxo de trabalho (KALAKOTA; WHINSTON, 1997).

De forma complementar, a partir da perspectiva de serviços, delimita-se o comércio eletrônico como uma ferramenta que integra o desejo de organizações e consumidores de reduzir custos, aumentando 
a qualidade dos produtos/serviços e a velocidade envolvida na entrega do serviço (KALAKOTA; WHINSTON, 1997; STRADER; SHAW, 1997). Por fim, sob a perspectiva da conectividade, pode-se considerar que o comércio eletrônico é um processo que viabiliza a comercialização de produtos e serviços e a troca de informações por meio da Internet (KALAKOTA; WHINSTON, 1997).

Partindo das quatro perspectivas propostas por Kalakota e Whinston (1997), Barnes-Vieyra e Claycomb (2001) conceituaram o comércio eletrônico como um processo de troca de informações e produtos/serviços viabilizado pelo uso da Internet, que interliga as organizações e seus parceiros de negócios, funcionários e mercados consumidores, eliminando restrições geográficas e temporais.

De forma complementar, Meng (2009) argumenta que o comércio eletrônico pode ser compreendido como um processo ou conjunto de atividades de negócios que utiliza tecnologias modernas de comunicação, dentre as quais se destaca a Internet, objetivando viabilizar trocas de maneira eficiente para todos os envolvidos.

Deste modo, verifica-se o conceito de comércio eletrônico está vinculado ao uso da Internet em transações de compra e venda, com o intuito de aumentar a eficiência e a eficácia das atividades transacionais, garantindo que as necessidades das partes sejam satisfeitas (MENG, 20009; BARNESVIEYRA; CLAYCOMB, 2001; KALAKOTA; WHINSTON, 1997; STRADER; SHAW, 1997).

Por outro lado, ampliando a abrangência do conceito, Applegate, McFarlan e McKenney (1996) argumentam que o comércio eletrônico engloba todas as atividades de pré-venda, venda e pós-venda, além das atividades de suporte aos negócios da organização, que são realizadas em um ambiente eletrônico.

Complementarmente, Albertin (2000) defende que o comércio eletrônico baseia-se na operacionalização de diferentes processos de negócio que fazem parte de uma cadeia de valor em um mercado eletrônico por meio da utilização intensiva de tecnologias de comunicação e informação, atendendo simultaneamente aos objetivos das organizações e dos mercados consumidores.

Neste sentido, constata-se que os conceitos mais abrangentes de comércio eletrônico incluem atividades que extrapolam a compra e venda de produtos/serviços, englobando todas as atividades que são realizadas em um mercado eletrônico e que agregam valor às transações e ao relacionamento desenvolvido entre uma organização e seus mercados consumidores, assim como entre uma organização e seus parceiros de negócios (ALBERTIN, 1998).

\subsection{Fatores que influenciam a adoção do comércio eletrônico}

Existem diversos fatores que motivam ou desmotivam um consumidor a realizar uma compra utilizando o comércio virtual. Segundo Merlo e Ceribeli (2014), tais fatores podem ser classificados em cinco grupos, sendo estes: utilitaristas, hedonistas, sociais, situacionais e experimentais.

Pela visão do utilitarismo, o consumidor busca razões lógicas em suas escolhas e ações no momento da compra. O valor utilitário tem motivação em variáveis como a variedade de produtos, preço justo, conveniência e qualidade. A partir desta perspectiva, o consumidor busca maximizar o valor utilitário a partir de benefícios tangíveis do produto ou serviço (GAYEN; SARKAR, 2011).

Corroborando esta proposta, Perea et al. (2004) afirmam que o comportamento utilitário consiste em um processo de compra no qual os objetivos dos consumidores são racionais e apoiados na lógica, buscando obter eficiência. Portanto, o consumo utilitário caracteriza-se por ter um objetivo específico, que é suprir uma necessidade básica ou a realização de uma tarefa funcional.

Ainda segundo Perea et al. (2004), os determinantes utilitaristas no comércio eletrônico podem ser classificados em duas dimensões: a utilidade percebida e a facilidade de uso. A utilidade percebida está relacionada a fatores como: economia monetária, menor tempo dedicado ao processo de compra e 
facilidade para se comparar produtos. Por sua vez, a facilidade de uso está relacionada à praticidade do processo de compra em si.

De acordo com Punj (2011), a utilidade percebida pode ser dividida em três variáveis: preocupação em (1) obter o melhor preço; (2) selecionar o melhor produto; e (3) economizar tempo no processo de compra.

Já a facilidade de uso está relacionada a ganhos no processo de compra obtidos pelos consumidores ao utilizar o comércio eletrônico. Alguns fatores importantes que englobam a facilidade de uso são: a velocidade para o consumidor encontrar o produto; e a facilidade e simplicidade de uso percebida pelo consumidor ao utilizar plataformas de compra virtuais (FLAVIÁN et al., 2006).

Outro grupo de fatores que é importante ser considerado refere-se aos determinantes hedonistas. Segundo Scarpi (2012), o valor hedônico está relacionado ao prazer na hora da compra; nesse caso, não existe apenas a preocupação em relação à conclusão da transação de forma eficiente; o consumidor está preocupado em obter uma experiência de compra divertida e prazerosa.

No comércio eletrônico, os elementos hedonistas estão relacionados ao fato de que muitos consumidores afirmam utilizar a Internet como ferramenta de compra principalmente em busca de distração e também por se sentirem estimulados durante o uso (PARSONS, 2002).

Segundo Hannah e Lybecker (2010), o indivíduo que passa mais tempo na Internet praticando outras atividades ligadas a seu entretenimento, como bate-papo e redes sociais, tende a associar uma satisfação maior ao processo de compras virtual e utilizar mais o comércio eletrônico como canal de compras.

Cabe acrescentar que, além dos fatores utilitaristas e hedônicos, não se deve descartar a importância do aspecto social na decisão dos e-consumidores de comprarem ou não via comércio eletrônico. As redes sociais passaram a influenciar o comportamento de compra dos consumidores no momento em que criaram um ambiente onde indivíduos trocam informações sobre produtos, interesses em comum, e relatam suas experiências no comércio virtual (SENECAL; NANTEL, 2004; DENNIS et al., 2009).

Segundo Lee et al. (2011), a influência dos determinantes sociais na adoção do e-commerce pode ser descrita como a maneira pela qual um determinado grupo social exerce, em um indivíduo, algum tipo de influência em sua decisão de comprar pela Internet.

Sendo assim, quando um indivíduo tem uma opinião positiva ou negativa a respeito do comércio eletrônico e tem contato com um grupo de referência que tem o pensamento similar ao dele, este indivíduo tende a reforçar a sua posição (positiva ou negativa), com base na influência que este grupo social causou a ele (LEE et al. 2011).

Por outro lado, quando o indivíduo se depara com uma opinião contrária a sua em um grupo de referência, a tendência é que este indivíduo dê menos importância à sua própria opinião e se torne propenso a ser favorável ao comércio virtual. Esse comportamento ocorre devido ao fato de os indivíduos buscarem a aceitação social em seus grupos de referência (LEE et al. 2011).

Além dos determinantes utilitaristas, hedonistas e sociais, outro grupo de determinantes importante para motivar ou desmotivar um consumidor a aderir ao comércio eletrônico são os chamados determinantes situacionais (MERLO; CERIBELI, 2014).

Wolfinbarger e Gilly (2001) apontam como principal variável situacional o tempo reduzido que o consumidor atual dispõe para realizar atividades além do trabalho. Por causa dessa pressão de tempo, o ambiente virtual se torna uma ferramenta de compra que permite ao consumidor realizar transações em menos tempo e sem precisar se locomover até a loja física.

A demanda por produtos específicos, que geralmente não são encontrados com facilidade nos 
mercados locais da maioria dos consumidores, também é um fator situacional que motiva a adoção do comércio eletrônico, pois na Internet o consumidor consegue encontrar muitos tipos de produtos específicos (PEREA et al., 2004).

Por fim, o último grupo de determinantes que influencia a adoção do comércio eletrônico pelo consumidor é composto pelos elementos experimentais. Segundo Shim et al. (2001), a intenção de compra no comércio eletrônico sofre influencia das experiências que determinado consumidor teve anteriormente neste ambiente, assim como da confiança atribuída a este modelo de negócios e ao risco percebido ao se realizarem transações online.

Shim et al. (2001) ainda afirmam que, caso as experiências anteriores do indivíduo sejam positivas, a tendência é que ele continue comprando via Internet. Perea et al. (2004) complementam que, caso a experiência anterior do consumidor for negativa, este irá criar uma resistência a futuras compras através da Internet, já que sua confiança neste canal de compras será reduzida.

De acordo com Lee e Turban (2001), a confiança é um dos fatores mais citados por consumidores para não realizarem compras utilizando a Internet. Além disso, as compras online estão associadas a um elevado nível de risco, pois os consumidores não podem verificar fisicamente a qualidade do produto ou monitorar o nível de proteção e segurança de suas informações pessoais e financeiras que são solicitadas nas transações de compra pela Internet (LEE; TURBAN, 2001).

A questão da confiança do consumidor em compras realizadas no comércio eletrônico deve perpassar duas dimensões: a confiança interpessoal (entre loja virtual e consumidor) e a confiança institucional (entre consumidor e a Internet) (McKNIGHT; CHERVANY, 2002).

\subsection{O comportamento caronista (free rider)}

Segundo Telser (1960), a competição e o alto custo das informações desmotivam os varejistas a oferecerem serviços de informações pré-venda sobre produtos ou serviços. O mesmo autor afirma ainda que o consumidor pode ser convencido a efetuar a compra com base nas informações fornecidas pelo varejista; entretanto, este consumidor pode comprar o mesmo produto em outra loja que ofereça uma condição de preço melhor. Neste sentido, o consumidor que escolhe comprar no varejista que disponibiliza o menor preço, mas não oferece as informações, "pega carona" (free ride) no varejista que forneceu todas as informações anteriormente (SPAHN, 2013; TELSER, 1960).

Quando um cliente troca o seu canal de compras após ter coletado informações, o varejista escolhido por ele está realizando a venda sem arcar com os custos das informações; sendo assim, este também é considerado como free rider (VAN BAAL; DACH, 2005).

No varejo, os consumidores "pegam carona" quando uma empresa não consegue cobrar por um serviço de informação pré-venda, e quando não consegue distinguir os consumidores free riders dos demais (BOYD, 1997; CADY, 1982; CARLTON; CHEVALIER, 2001).

Van Baal e Dach (2005) afirmam que, geralmente, os varejistas não conseguem cobrar por informações fornecidas antes da venda. E, devido ao fato de que a intenção do indivíduo não pode ser prevista, é difícil identificar quais consumidores são caronistas e quais não são.

O comportamento free rider pode acontecer em diferentes canais de compra, sendo caracterizado pelo uso de alguma informação sobre um produto/serviço que foi coletada em um determinado canal e utilizada como base para realizar a compra em outro (SPAHN, 2013; Van BAAL; DACH, 2005).

No varejo tradicional, o comportamento caronista acontece quando um indivíduo coleta todas as informações julgadas por ele como relevantes, tem um contato físico com o produto para avaliá-lo, e realiza testes de sua aplicabilidade; após decidir se irá comprar o produto, este consumidor realiza sua 
compra através de uma loja virtual que ofereça o mesmo produto com alguma vantagem em relação à loja física, como, por exemplo, um menor preço (SPAHN, 2013; BAKOS, 2001).

No ambiente virtual, onde existe grande variabilidade de produtos e preços, alguns consumidores realizam buscas para coletar informações sobre algum produto/serviço e, em seguida, buscam o site que ofereça o melhor preço ou outra vantagem. Este comportamento se caracteriza como caronista ou free rider, e faz com que as empresas forneçam informações genéricas e padronizadas sobre os produtos ofertados, buscando diminuir a ocorrência deste comportamento (SPAHN, 2013; BAKOS, 2001).

Os efeitos adversos do comportamento free rider apresentam-se de diferentes formas. Na perspectiva dos varejistas, o efeito predominante é a perda de vendas, que acontecem quando um cliente com algum interesse em realizar uma compra não a realiza. Além disso, varejistas que atuam no mercado físico tem que arcar com custos de oportunidade, quando um vendedor ocupa seu tempo atendendo um consumidor free rider, quando poderia estar dando sua assistência a um consumidor que efetuaria a compra (VAN BAAL; DACH, 2005).

Complementarmente, Singley e Williams (1995) afirmam que o comportamento free rider aumenta a disparidade de preços entre as empresas que pegam carona nas informações das outras e as que fornecem essas informações. Além disso, segundo Spahn (2013), o comportamento free rider promove uma redução no número de informações disponibilizadas aos consumidores, o que, consequentemente, causa uma queda na demanda de determinados produtos no mercado.

No contexto do comércio eletrônico, o comportamento free rider tem como a questão mais ressaltada o caso de consumidores que "pegam carona" nos serviços oferecidos no varejo tradicional, coletando todas as informações sobre o produto e, depois de terem contato físico com o mesmo, efetuam a compra em lojas virtuais (BAKOS, 2001).

Por outro lado, Verhoef et al. (2007) afirmam que a troca de canais de compras mais comum no comércio eletrônico acontece quando um consumidor procura todas as informações sobre o produto na Internet e realiza a compra em um loja física.

Contudo, Carlton e Chevalier (2001) argumentam que, no comércio eletrônico, o comportamento caronista ocorre principalmente entre lojas eletrônicas, sendo que os custos das lojas online são em grande parte fixados, devido ao fato de que as informações online são consideradas bens públicos.

Conforme pode ser verificado na literatura, existem diferentes formas de comportamento caronista; neste trabalho, porém, será estudado exclusivamente o comportamento free rider entre websites, descrito por Carlton e Chevalier (2001), Bakos (2001), Van Baal e Dach (2005) e Spahn (2013).

\section{ASPECTOS METODOLÓGICOS}

Para atingir o objeto proposto, optou-se pela realização de uma pesquisa descritiva de caráter quantitativo, à medida que se teve como intuito realizar a descrição do objeto de estudo, explicitando características e correlações relevantes entre variáveis relevantes, recorrendo, para isso, ao tratamento estatístico dos dados coletados (SANTOS; CANDELORO, 2006).

Como método de pesquisa, optou-se pelo levantamento de campo ou survey, que, segundo Malhotra (2006), é um método que utiliza questionários autoadministrados para coleta de dados, ou seja, que não dependem da assistência de entrevistadores para serem respondidos.

A coleta dos dados foi realizada de forma virtual, ou seja, a divulgação do questionário ocorreu por meio da rede social Facebook. Para isso, o questionário foi formatado utilizando-se a plataforma Google Docs e, em seguida, enviado para todos os contatos dos pesquisadores, junto de uma breve explicação sobre o estudo. Para garantir maior abrangência da coleta de dados, os pesquisadores 
solicitaram a seus contatos que compartilhassem o link do questionário enviado, para que seus respectivos contatos também pudessem respondê-lo.

A divulgação do questionário no Facebook ocorreu durante todo o mês de outubro de 2014, sendo que, neste intervalo de tempo, o link para respondê-lo foi publicado a cada dois dias, assim como a solicitação para que o mesmo fosse compartilhado por seus contatos.

O método de amostragem utilizado foi não probabilístico por conveniência. Segundo Viana (2011), a escolha pela amostragem não probabilística em pesquisas quantitativas justifica-se por sua simplicidade operacional e pela dificuldade associada à obtenção de amostras probabilísticas, considerando que normalmente não é possível obter uma estrutura de amostragem completa.

O tamanho da amostra foi definido seguindo as recomendações de Hair Junior et al. (2009), que sugerem que, quando se objetiva aplicar técnicas estatísticas multivariadas para analisar os dados coletados, o tamanho da amostra deve ter entre 10 e 20 vezes a quantidade de variáveis incluídas na pesquisa. Considerando que, nesta pesquisa, incluíram-se no instrumento de coleta de dados 24 variáveis (dependentes ou independentes) cujas relações seriam analisadas por meio de técnicas estatísticas multivariadas, definiu-se como tamanho mínimo da amostra 240 elementos, o que representaria uma proporção de 10 vezes a quantidade de variáveis de pesquisa.

A construção do instrumento de coleta de dados baseou-se no referencial teórico previamente analisado; a escala utilizada foi a de Likert de cinco pontos, cujos extremos são (1) "discordo totalmente" e (5) "concordo totalmente". Malhotra (2006) apontam como vantagens do uso da escala de Likert a facilidade em sua construção, aplicação e compreensão por parte dos respondentes, independentemente do nível de instrução.

Para validar o instrumento de coleta de dados elaborado, realizou-se um pré-teste com dez indivíduos, com o intuito de verificar se o questionário elaborado não continha questões ambíguas ou de difícil compreensão. Após o pré-teste, os itens que se enquadravam nas situações supracitadas foram alterados e um novo pré-teste foi realizado, também com dez indivíduos. A amostra dos dois pré-testes realizados foi composta por estudantes da Universidade Federal de Ouro Preto.

$\mathrm{Na}$ construção do instrumento de coleta de dados, primeiramente foram elaboradas questões para analisar os antecedentes da adoção do comércio eletrônico, apresentadas na Figura 01, com o intuito de verificar se alguns destes fatores podem também explicar o comportamento caronista.

Figura 01 - Questões para mensurar os antecedentes da adoção do e-commerce.

(Continua)

\begin{tabular}{|c|c|}
\hline Questões & Referencial teórico \\
\hline 1. Considero ser mais prático efetuar compras através da Internet. & $\begin{array}{c}\text { Punj (2011); } \\
\text { Perea et al. (2004). }\end{array}$ \\
\hline 2. Tenho facilidade em utilizar a Internet para realizar compras. & $\begin{array}{l}\text { Flavián et al. (2006); Perea et } \\
\text { al. (2004). }\end{array}$ \\
\hline $\begin{array}{l}\text { 3. Gastaria menos tempo comprando o mesmo produto na Internet do } \\
\text { que se fosse comprar em uma loja física. }\end{array}$ & $\begin{array}{c}\text { Punj (2011); } \\
\text { Perea et al. (2004). }\end{array}$ \\
\hline $\begin{array}{l}\text { 4. Os preços encontrados no comércio eletrônico são menores do que no } \\
\text { comércio físico. }\end{array}$ & $\begin{array}{c}\text { Punj (2011); } \\
\text { Perea et al. (2004). }\end{array}$ \\
\hline $\begin{array}{l}\text { 5. A reputação do site é importante para que eu efetue minha compra na } \\
\text { Internet. }\end{array}$ & $\begin{array}{l}\text { McKnight e Chervany (2002); } \\
\text { Lee e Turban (2001). }\end{array}$ \\
\hline 6. Só compraria na Internet produtos que já conheço fisicamente. & $\begin{array}{l}\text { McKnight e Chervany (2002); } \\
\text { Lee e Turban (2001). }\end{array}$ \\
\hline
\end{tabular}


Figura 01 - Questões para mensurar os antecedentes da adoção do e-commerce.

(Conclusão)

\begin{tabular}{|c|c|}
\hline $\begin{array}{l}\text { 7. Não me sinto desconfortável em fornecer meus dados do cartão de } \\
\text { crédito para realizar compras em lojas virtuais. }\end{array}$ & $\begin{array}{l}\text { McKnight e Chervany (2002); } \\
\text { Lee e Turban (2001). }\end{array}$ \\
\hline $\begin{array}{l}\text { 8. No comércio eletrônico, tenho acesso a mais informações sobre } \\
\text { produtos do que no comércio físico. }\end{array}$ & $\begin{array}{c}\text { Punj (2011); } \\
\text { Perea et al. (2004). }\end{array}$ \\
\hline Considero arriscado comprar produtos de alto valor em lojas virtuais. & $\begin{array}{l}\text { McKnight e Chervany (2002); } \\
\text { Lee e Turban (2001). }\end{array}$ \\
\hline 10. Na Internet tenho acesso a mais produtos do que nas lojas físicas. & $\begin{array}{l}\text { Ceribeli e Merlo (2014); } \\
\text { Punj (2011). }\end{array}$ \\
\hline $\begin{array}{l}\text { 11. Encontro produtos específicos com maior facilidade na Internet do } \\
\text { que em lojas físicas. }\end{array}$ & $\begin{array}{l}\text { Merlo e Ceribeli (2014); Perea } \\
\text { et al. (2004). }\end{array}$ \\
\hline $\begin{array}{r}\text { 12. Não me sinto desconfo } \\
\text { realizar ce }\end{array}$ & $\begin{array}{l}\text { McKnight e Chervany (2002); } \\
\text { Lee e Turban (2001). }\end{array}$ \\
\hline $\begin{array}{r}\text { 13. Devido ao design dos sites modernos, co } \\
\text { uma experiência muito ag }\end{array}$ & $\begin{array}{l}\text { Scarpi (2012); } \\
\text { Parsons (2002). }\end{array}$ \\
\hline $\begin{array}{r}\text { 14. Considero os pra } \\
\text { melho }\end{array}$ & $\begin{array}{c}\text { Punj (2011); } \\
\text { Perea et al. (2004). }\end{array}$ \\
\hline 15. Considero mais fácil encontrar produtos de qualidade na Internet. & $\begin{array}{c}\text { Punj (2011); } \\
\text { Perea et al. (2004). }\end{array}$ \\
\hline 16. Realizar compras na Internet é uma atividade divertida. & $\begin{array}{l}\text { Scarpi (2012); } \\
\text { Parsons (2002). }\end{array}$ \\
\hline $\begin{array}{l}\text { 17. Utilizo com frequência redes sociais para buscar informações que } \\
\text { me ajudem a escolher melhor o que e onde comprar. }\end{array}$ & $\begin{array}{l}\text { Hannah e Lybecker (2010); } \\
\text { Dennis et al. (2009). }\end{array}$ \\
\hline $\begin{array}{l}\text { 18. Antes de comprar, procuro na Internet recomendações de terceiros } \\
\text { sobre produtos e lojas virtuais. }\end{array}$ & $\begin{array}{l}\text { Hannah e Lybecker (2010); } \\
\text { Dennis et al. (2009). }\end{array}$ \\
\hline $\begin{array}{l}\text { 19. A maioria das experiências que já vivenciei em ambientes virtuais } \\
\text { (de compra ou não) foi positiva. }\end{array}$ & $\begin{array}{l}\text { Perea et al. (2004); } \\
\text { Shim et al. (2001). }\end{array}$ \\
\hline $\begin{array}{l}\text { 20. Antes de comprar, levo em consideraçãa } \\
\text { quem convivo diarian }\end{array}$ & $\begin{array}{l}\text { Hannah e Lybecker (2010); } \\
\text { Dennis et al. (2009). }\end{array}$ \\
\hline
\end{tabular}

Fonte: Elaborado pelos pesquisadores com base no referencial teórico.

Em seguida, foram elaboradas questões para mensurar o comportamento caronista, apresentadas na Figura 02.

Figura 02 - Questões para mensurar o comportamento free rider ou caronista.

\begin{tabular}{|c|c|}
\hline Questões & Referencial Teórico \\
\hline $\begin{array}{l}\text { 1. Mesmo sem intenção de comprar, costumo permanecer muito tempo } \\
\text { navegando em diferentes lojas virtuais para coletar informações sobre os } \\
\text { produtos que desejo. }\end{array}$ & \multirow{4}{*}{$\begin{array}{l}\text { Spahn (2013); } \\
\text { Van Baal e Dach (2005); } \\
\text { Bakos (2001). }\end{array}$} \\
\hline $\begin{array}{l}\text { 2. Busco informações sobre o produto que estou procurando em diversos } \\
\text { sites antes de realizar uma compra no comércio eletrônico. }\end{array}$ & \\
\hline $\begin{array}{l}\text { 3. Prefiro comprar em um site em que já confio, mesmo que este site não } \\
\text { disponibilize muitas informações sobre os produtos vendidos. }\end{array}$ & \\
\hline $\begin{array}{l}\text { 4. Pesquiso em diversas lojas virtuais para encontrar o menor preço antes de } \\
\text { realizar uma compra. }\end{array}$ & \\
\hline
\end{tabular}

Fonte: Elaborado pelos pesquisadores com base no referencial teórico. 
Também foi inserida, no início do instrumento de coleta de dados, uma questão filtro, questionando se o indivíduo já havia realizado compras no comércio eletrônico. Com isso, foi possível excluir aqueles que nunca compraram pela Internet e constituir a amostra apenas de respondentes que já tiveram experiências no comércio eletrônico.

A análise dos dados obtidos nesta pesquisa pode ser dividida em duas etapas: na primeira, as variáveis propostas no estudo para mensurar o comportamento caronista dos indivíduos foram agrupadas em um único fator, denominado Comportamento Caronista; na segunda, foi realizada uma análise de regressão múltipla para verificar se existe relação entre os antecedentes da adoção do comércio eletrônico e o comportamento caronista dos e-consumidores.

Na primeira etapa, foi utilizada a técnica estatística de Análise Fatorial Exploratória. Hair Junior et al. (2009) definem esta ferramenta como uma técnica que busca reduzir um determinado número de variáveis em uma quantidade menor de dimensões, sendo estas denominadas como fatores, resumindo os dados de forma a facilitar a análise, sem que ocorra perda de informações. Como exposto anteriormente, no presente estudo, tal técnica estatística foi aplicada para se reduzir em um único fator as variáveis que mensuram o comportamento caronista dos indivíduos.

Na segunda etapa, a ferramenta estatística utilizada foi a Regressão Múltipla, com o objetivo de desenvolver uma equação que explicasse a relação entre as variáveis que motivam a adoção do comércio eletrônico e o comportamento caronista, tema central deste estudo.

Segundo Gujarati (2006), a equação desenvolvida com a utilização da técnica de Regressão Múltipla tem a seguinte estrutura geral:

$$
Y=\beta 1+\beta 2 X 2 i+\beta 3 X 3 i+\cdots+\beta n X n i+u i
$$

Nesta pesquisa, a variável dependente $(\mathrm{Y})$ representou o fator Comportamento Caronista, e as variáveis independentes ou explanatórias (X2 a Xn), as variáveis que explicam a adoção do comércio eletrônico. Já os valores relacionados aos coeficientes parciais de regressão $(\beta)$ medem a importância das variáveis independentes Xn (variáveis que motivam a adoção do comércio eletrônico) em relação à variável dependente Y (fator comportamento caronista) (GUJARATI, 2006; HAIR JUNIOR et al., 2005).

É importante ressaltar que o erro (ui) que aparece no modelo de Regressão Múltipla é, para fins de estudos, igualado a zero, e que a variável $\beta_{1}$ representa a constante do modelo, sendo um valor que não está relacionado a nenhuma variável independente específica (GUJARATI, 2006; HAIR JUNIOR et al., 2005).

\section{APRESENTAÇÃO E DISCUSSÃO DOS RESULTADOS}

O questionário aplicado nesta pesquisa atingiu uma amostra de 307 indivíduos, principalmente habitantes das regiões dos Inconfidentes e do Alto do Paraopeba do estado de Minas Gerais (62\% da amostra), concentrados nas cidades de Ouro Preto, Ouro Branco e Mariana. Também foram obtidos questionários respondidos por habitantes do Estado de São Paulo (29\%) e Espírito Santo (9\%).

Quanto ao gênero, do total de 307 questionários obtidos, 42\% foram respondidos por indivíduos do gênero masculino e 58\%, por indivíduos do gênero feminino. No quesito escolaridade, a amostra foi composta principalmente por indivíduos com ensino superior completo (34\%), seguidos por indivíduos com ensino médio (32\%) e indivíduos ensino superior incompleto (29\%); indivíduos com pós-graduação totalizaram $5 \%$ da amostra. 
Em relação ao estado civil dos respondentes, $53 \%$ são solteiros, $46 \%$, casados, e $1 \%$, viúvos. A idade dos respondentes variou de 16 a 54 anos, com uma idade média de 29 anos, o que representa uma amostra relativamente jovem.

Depois de caracterizar a amostra da pesquisa, seguiu-se para a realização da Análise Fatorial Exploratória (AFE), com o intuito de agrupar as variáveis relacionadas ao construto comportamento caronista.

Objetivando verificar a aplicabilidade da Análise Fatorial para a análise dos dados coletados, foi realizado inicialmente o teste de esfericidade de Bartlett (p-valor obtido de 0,000), a partir do qual se constatou, a um nível de 5\% de significância (significância adotada em todos os testes neste trabalho), que havia correlações suficientemente fortes entre as variáveis propostas, justificando a utilização da AFE.

Foi realizado em seguida o teste Kaiser-Meyer-Olkin (KMO), utilizado para medir a adequação da amostra para se aplicar a Análise Fatorial. O KMO calculado foi de 0,611, o que indicou que a técnica de análise estatística supramencionada era adequada para o conjunto de dados estudados.

Na sequência, calculou-se o Alfa de Cronbach, com o intuito de verificar se as variáveis mensuravam o mesmo construto. O Alfa encontrado para as quatro variáveis que se desejava agrupar foi de 0,460, indicando baixa confiabilidade em relação à consistência interna entre elas, sendo que o limite inferior recomendado para o Alfa de Cronbach é de 0,6 (HAIR JUNIOR et al., 2009).

Também foram analisadas as comunalidades das variáveis, que medem a quantidade de variância em cada variável que é explicada pela solução fatorial, sendo recomendado que apresentem valor mínimo de 0,5 (HAIR JUNIOR et al., 2009). Como a variável 3 obteve um valor muito reduzido (próximo de zero), optou-se por excluí-la e realizar nova Análise Fatorial.

A nova AFE incluiu apenas três variáveis. Foram realizados os testes de esfericidade de Bartlett e KMO, além do cálculo do Alfa de Cronbach; os resultados obtidos foram respectivamente, 0,000; 0,794; e 809. Desta forma, verifica-se a adequação da técnica estatística Análise Fatorial para os dados coletados e as variáveis utilizadas.

$\mathrm{Na}$ etapa seguinte, foram analisadas as comunalidades das variáveis. Como todas as variáveis apontaram comunalidade superior a 0,5 , que é o limite mínimo recomendado, não foi preciso realizar novas exclusões.

A solução fatorial adotada neste trabalho, que incluiu um único fator denominado de Comportamento Caronista, conseguiu explicar $63,56 \%$ da variância total dos dados coletados, o que aponta que o fator obtido possui poder moderado de explicação em relação às variáveis agrupadas.

A Análise Fatorial realizada originou escores fatoriais, que foram utilizados como valores da variável dependente na Análise de Regressão Múltipla que foi realizada subsequentemente, com o objetivo de testar a relação entre os antecedentes da adoção do comércio eletrônico e o comportamento caronista.

A regressão teve como variável dependente o fator criado a partir do agrupamento das variáveis que mensuravam o comportamento caronista e, como variáveis independentes, a variáveis que mensuravam os antecedentes da adoção do comércio eletrônico. O método Stepwise foi o escolhido para desenvolver a análise estatística supramencionada. Neste método as variáveis independentes mais relevantes são adicionadas ao modelo de regressão por etapas, dando origem a vários modelos de regressão (HAIR JUNIOR et al., 2009).

Foram gerados cinco modelos de regressão para os dados referentes à adoção do comércio eletrônico; entretanto, para fins de análise, foi escolhido o quinto modelo fornecido pelo software estatístico SPSS, pois aquele foi o que apresentou o maior coeficiente de determinação ajustado ( ${ }^{2}$ ajustado). 
Analisando o coeficiente de determinação ajustado do modelo cinco ( $\mathrm{R}^{2}$ ajustado de 0,478$)$, é possível afirmar que o modelo de regressão supracitado é capaz de explicar $47,8 \%$ da variação no comportamento caronista dos e-consumidores.

Com o objetivo de validar o modelo de regressão obtido, foi realizado o teste ANOVA. A um nível de significância 0,05 , rejeitou-se a hipótese nula e, se concluiu que existia regressão para, pelo menos, uma das variáveis independentes inseridas no modelo cinco. A estatística F calculada foi de 21,9, o que significa que a variação no comportamento caronista explicada pelo modelo cinco é, aproximadamente, 22 vezes maior do que a variação não explicada, indicando que o modelo de regressão possui poder de explicação razoável.

Foi analisada também a multicolinearidade apresentada pelas variáveis incluídas no modelo de regressão desenvolvido, adotando-se duas medidas: Tolerância e Fator de Inflação da Variância (FIV). Segundo Hair Junior et al., (2005), o valor da Tolerância deve ser superior a 0,10 e o valor do FIV, inferior a 5,0; caso contrário, pode-se considerar que há indícios de multicolinearidade significativa. Considerando que os valores obtidos nos testes de Tolerância e FIV estavam dentro dos limites recomendados, concluiu-se que não havia multicolinearidade relevante no modelo de regressão analisado.

Após a verificação de que não havia multicolinearidade associada às variáveis independentes do modelo de regressão desenvolvido, os coeficientes beta foram testados com o objetivo de se verificar sua significância estatística. A hipótese nula testada foi a de que não existe relação estatisticamente significativa entre cada uma das variáveis independentes que fazem parte do modelo de regressão analisado e a variável dependente (comportamento caronista) $(\beta n=0)$. Como hipótese alternativa, foi considerada a alegação de que há relação estatisticamente significativa entre cada variável independente e a variável dependente (comportamento caronista) $(\beta n \neq 0)$. A Tabela 01 apresenta os valores dos coeficientes beta e os respectivos p-valores.

Tabela 01 - Coeficientes beta e p-valores.

\begin{tabular}{c|c|c}
\hline Variável & Coeficiente Beta & Sig. ou p-valor \\
\hline Conveniência & 0,518 & 0,000 \\
Preços & 0,291 & 0,005 \\
Redes sociais & 0,150 & 0,013 \\
Conhecimento prévio & 0,160 & 0,011 \\
Segurança & 0,146 & 0,017 \\
Recomendações & 0,171 & 0,032 \\
\hline
\end{tabular}

Fonte: Elaborado pelos autores.

Considerando um nível de significância de 0,05, rejeitaram-se as hipóteses nulas de não significância dos coeficientes beta. Com isso, é possível afirmar que cada um dos coeficientes de regressão obtidos é estatisticamente significativo, ou seja, existe relação significativa entre cada uma das variáveis independentes incluídas no modelo de regressão e a variável dependente comportamento caronista.

Após constatar que todas as variáveis independentes são estatisticamente relevantes e exercem influência sobre o comportamento caronista, foi feita a análise da equação desenvolvida, que pode ser apresentada da seguinte forma:

$$
\mathrm{Y}=-5,958+0,681 \mathrm{X} 1+0,346 \mathrm{X} 2+0,249 \mathrm{X} 3+0,187 \mathrm{X} 4+0,189 \mathrm{X} 5+0,208 \mathrm{X} 6
$$


Sendo:

$\mathrm{Y}$ - comportamento caronista;

$X_{1}$ - percepção de que o comércio eletrônico reduz os esforços envolvidos na compra;

$\mathrm{X}_{2}$ - percepção de que os preços são menores no comércio eletrônico;

$\mathrm{X}_{3}$ - uso de redes sociais para buscar informações;

$\mathrm{X}_{4}$ - preferência por produtos previamente conhecidos;

$\mathrm{X}_{5}$ - baixa percepção de risco financeiro nas transações eletrônicas;

$\mathrm{X}_{6}$ - busca de informações prévias com terceiros.

Analisando o modelo de regressão obtido, constatou-se que consumidores que veem no comércio eletrônico uma oportunidade de comprar produtos mais baratos tendem a adotar o comportamento caronista, pois, ao invés de valorizarem sites que lhes forneçam mais informações, procurarão sites mais baratos, mesmo que faltem informações.

Consumidores com baixa percepção de risco em relação a compras no comércio eletrônico também tendem a apresentar o comportamento caronista, pois estariam dispostos a comprar em sites não tradicionais que lhe ofereçam alguma outra vantagem, como menores preços ou entrega mais rápida, mesmo que este site seja potencialmente inseguro.

Deste modo, constata-se que os consumidores mais propensos a adotar o comportamento caronista são aqueles que não estão muito preocupados com risco e que, ao mesmo tempo, valorizam muito a questão monetária.

A regressão obtida também permite observar que indivíduos que valorizam muito informações prévias tendem a adotar o comportamento caronista, pois, como buscam informações em redes sociais, com terceiros e em suas próprias experiências anteriores, também tenderão a buscar informações em diferentes sites antes de efetuarem a compra. Com isso, conclui-se que os consumidores mais preocupados com informações são aqueles que tendem a adotar o comportamento caronista.

Além disso, a percepção de que o comércio eletrônico reduz os esforços envolvidos na compra foi outro fator encontrado como antecedente do comportamento caronista. A primeira análise a respeito desta variável foi que a mesma era contraditória, visto que, se o consumidor opta por comprar via Internet por perceber que, desta forma, reduz esforços, ele não estaria disposto a se esforçar mais buscando informações em alguns sites e, depois, preços menores em outro site.

Uma reflexão mais profunda permitiu que fosse delimitada uma hipótese para explicar tal comportamento. O que se concluiu foi que os consumidores que são atraídos ao comércio eletrônico pela conveniência estariam mais abertos para as possibilidades nesta modalidade de varejo e, consequentemente, mais dispostos a navegarem em mais sites; ao contrário, indivíduos que consideram ser trabalhoso realizar uma compras via Internet, tenderiam a simplificar o processo de compra, efetuando o pedido sem navegar em muitos sites diferentes.

Analisando conjuntamente as variáveis identificadas como antecedentes do comportamento caronista, conclui-se que, tenderão a adotar este comportamento, aqueles consumidores que valorizam questões monetárias e informações para embasar a compra, que mantêm baixo grau de risco percebido em relação ao comércio eletrônico, e que tem a percepção de que comprar nesta modalidade envolve poucos esforços. 


\section{CONSIDERAÇÕES FINAIS}

A presente pesquisa teve como contexto o crescimento significativo que o comércio eletrônico apresentou nos últimos anos, associado à escassez de pesquisas que estudam o comportamento free rider nesta modalidade de varejo. A partir de tal contexto, delimitou-se como objetivo de pesquisa analisar se os fatores que explicam a adoção do comércio eletrônico são também capazes de explicar o comportamento caronista do e-consumidor.

A partir da análise estatística, constatou-se que existem alguns fatores que motivam os consumidores a optar pelo comércio eletrônico e que também influenciam diretamente a adoção do comportamento caronista.

Primeiramente, verificou-se que consumidores que são motivados a comprar no comércio eletrônico devido à sua percepção de que neste canal de compras é possível encontrar melhores preços e que valorizam muito as informações prévias obtidas, tendem a adotar o comportamento caronista, pois estes consumidores, depois de buscarem muitas informações para embasarem sua decisão, comprariam no site que lhes fosse mais vantajoso monetariamente.

Além disso, foi verificado que consumidores que associam baixo risco a compras no comércio eletrônico também tendem a apresentar o comportamento caronista. Neste caso, o consumidor que não tem grande preocupação com a segurança de seus dados ao comprar na Internet não tem problemas em pesquisar em diversos sites para encontrar a vantagem que ele procura, realizando sua compra independentemente da reputação da loja virtual.

Outro fator encontrado como motivador para o comportamento caronista é a percepção de que comprar via Internet demanda menos esforços do que outras modalidades de comércio, pois o consumidor que não considera conveniente realizar compras no comércio eletrônico tenderia a realizar sua compra no comércio físico, ou iria diretamente para um site que já conheça.

Analisando conjuntamente todos os fatores identificados como antecedentes da adoção do comércio eletrônico e do comportamento caronista, pode-se traçar o seguinte perfil do e-consumidor prédisposto a adotar tal comportamento: indivíduo muito preocupado com obter preços mais baixos no comércio eletrônico e que valoriza, no momento de tomar sua decisão de compra, a posse de várias informações de diversas fontes; apesar de ser meticuloso no que se refere a informações prévias, este econsumidor não associa grandes riscos às transações online e, por isso, pode estar mais disposto a comprar em sites menos conhecidos, desde que nestes os preços praticados sejam menores; além disso, este econsumidor tende a associar maior conveniência às compras online e, por isso, estaria disposto a navegar em vários sites.

Para estudos futuros, sugere-se que seja feito o estudo do comportamento caronista em outras direções, como do comércio físico para o eletrônico ou vice e versa, buscando verificar se os fatores apontados nesta pesquisa também se aplicam aos diferentes ambientes onde ocorre este comportamento. Complementarmente, recomenda-se que sejam testados outros fatores como possíveis preditores do comportamento caronista, além dos que foram propostos neste trabalho (relacionados à adoção do comércio eletrônico), buscando ampliar o escopo da análise.

Para finalizar, destaca-se que a principal contribuição desta pesquisa reside no fato de que foi abordado um tema ainda pouco explorado na academia, seja na literatura nacional ou internacional, contribuindo para reduzir tal lacuna teórica no estudo do comportamento do e-consumidor. 


\section{REFERÊNCIAS}

ALBERTIN, A. L. Comércio eletrônico: modelo, aspectos e contribuições de sua aplicação. 2. ed. São Paulo: Atlas, 2000.

ALBERTIN, A. L. Comércio eletrônico: benefícios e aspectos de sua aplicação. Revista de Administração de Empresas - RAE, v. 38, n. 1, p. 52-63, 1998.

APPLEGATE, L. M.; McFARLAN, F. W.; McKENNEY, J. L. Electronic commerce: building blocks of new business opportunity. Journal of Organizational Computing and Electronic Commerce, v.6, n. 1, p. 1-10, 1996.

BAKOS, Y. The emerging landscape for retail e-commerce. Journal of Economic Perspectives, v. 15, n. 1, p. 69-80, 2001.

BARNES-VIEYRA, P.; CLAYCOMB, C. Business-to-business e-commerce: models and managerial decisions. Business Horizons, v. 44, n. 3, p.13-20, 2001.

BOYD, D. W. From" mom and pop" to Wal-Mart: The impact of the Consumer Goods Pricing Act of 1975 on the retail sector in the United States. Journal of Economic Issues, v. 31, n. 1, p. 223-232, 1997.

CADY, J. F. Reasonable rules and rules of reason: vertical restrictions on distributors. The Journal of Marketing, v. 46, p. 27-37, 1982.

CARLTON, D. W.; CHEVALIER, J. A. Free riding and sales strategies for the Internet. The Journal of Industrial Economics, v. 49, n. 4, p. 441-461, 2001.

DENNIS, C.et al. E-consumer behavior. European Journal of Marketing, v. 43, n. 9/10, p. 1121-1139, 2009.

EBIT. WebShoppers 2016. Disponível em: http://www.ebit.com.br/webshoppers. Acesso em: 08 abr. 2016.

FLAVIÁN, C.; GUINALÍU, M.; GURREA, R. The role played by perceived usability, satisfaction and consumer trust on website loyalty. Information \& Management, v. 43, n. 1, p. 1-14, 2006.

GAYEN, B.; SARKAR, S. Boundary mixing by density overturns in an internal tidal beam. Geophysical Research Letters, v. 38, n. 14, 2011.

GUJARATI, D. N. Economia Básica. Rio de Janeiro: Elsevier, 2006.

HAIR JUNIOR, J. F.et al. Fundamentos de métodos de pesquisa em administração. Porto Alegre: Bookman, 2005.

HAIR JUNIOR, J. F.et al. Análise multivariada de dados. 6. ed. Porto Alegre: Bookman, 2009.

HANNAH, B.; LYBECKER, K. M. Determinants of recent online purchasing and the percentage of income spent online. International Business Research, v. 3, n. 4, p. 60-71, 2010.

KALAKOTA, R.; WHINSTON, A. B. Electronic commerce: a manager's guide. Addison Wesley: Reading, 1997.

LEE, M. K. O.et al. Consumer's decision to shop online: the moderating role of positive informational social influence. Information \& Management, v. 48, p. 185-191, 2011. 
LEE, M. K. O.; TURBAN, E. A trust model for consumer Internet shopping. International Journal of Electronic Commerce, v. 6, n. 1, p. 75-91, 2001.

MALHOTRA, N. K. Pesquisa de marketing: uma orientação aplicada. 4. ed., Porto Alegre, Bookman, 2006.

McKNIGHT, D.; CHERVANY, N. What trust means in e-commerce customer relationships: an interdisciplinary conceptual typology. International journal of electronic commerce, v. 6, p. 35-60, 2002.

MENG, X. Developing model of e-commerce e-marketing. International Symposium on Information Processing (ISIP’09). Proceedings of... China, p. 225-228, August, 2009.

MERLO, E; CERIBELI, H. Comportamento do consumidor. Rio de Janeiro: LTC, 2014.

PARSONS, A. G. Non-functional motives for online shoppers: why we click. Journal of Consumer Marketing, v. 19, n. 5, p. 380-392, 2002.

PEREA, T. M.; DELLAERT, B. G. C.; RUYTER, K. What drives consumers to shop online? A literature review. International Journal of Service Industry Management, v. 15, n. 1, p. 102-121, 2004.

PUNJ, G. Effect of consumer beliefs on online purchase behavior: the influence of demographic characteristics and consumption values. Journal of Interactive Marketing, v. 25, p. 134-144, 2011.

SANTOS, V.; CANDELERO, R. Trabalhos acadêmicos: uma orientação para a pesquisa e normas técnicas. Porto Alegre: Assessoria, 2006.

SCARPI, D. Work and fun on the Internet: the effects of utilitarianism and hedonism online. Journal of Interactive Marketing, v. 26, n. 1, p. 53-67, 2012.

SENECAL, S.; NANTEL, J. The influence of online product recommendations on consumer's online choices, Journal of Retailing, v. 80, p. 159-169, 2004.

SHIM, S.et al.Na online pre-purchase intentions model: the role of intention to search. Journal of Retailing, v. 77, n. 3, p. 397-416, 2001.

SINGLEY, R. B.; WILLIAMS, M. R. Free riding in retail stores: An investigation of its perceived prevalence and costs. Journal of Marketing Theory and Practice, v. 3, p. 64-74, 1995.

SPAHN, S. Cross-channel free-riding consumer behavior in a multichannel environment: An investigation of shopping motives, sociodemographics and product categories. Journal of Retailing and Consumer Services, v. 20, n. 6, p. 570-578, 2013.

STRADER, T. J.; SHAW, M. J. Characteristics of electronic markets. Decision Support Systems, v. 21, p. 185-198, 1997.

TELSER, L. G. Why should manufacturers want fair trade?. Journal of law and economics, v. 3, p. 86$105,1960$.

VAN BAAL, S.; DACH, C. Free-riding and customer retention across retailer's channels. Journal of Interactive Marketing, v. 19, p. 75-85, 2005.

VERHOEF, P. C.et al. Customer experience creation: Determinants, dynamics and management strategies. Journal of Retailing, v. 85, n. 1, p. 31-41, 2009. 
VIANA, A. B. N. Pesquisa quantitativa aplicada ao varejo. In: MERLO, E. M. (Org.). Administração de varejo com foco em casos brasileiros. Rio de Janeiro: LTC, 2011.

WOLFINBARGER, M. F.; GILLY, M. C. Shopping online for freedom, control, and fun. California Management Review, v. 43, n. 2, p. 34-55, 2001. 